\title{
De los medios a las plataformas. Del control del gatekeeping a la conversación descontrolada
}

\author{
Daniel Mazzone Vivas \\ Universidad ORT Uruguay \\ mazzone@ort.edu.uy
}

Recibido: 25/2/2018 / Aceptado: 9/4/2018

doi: 10.26439/contratexto2018.n029.1824

\begin{abstract}
RESUMEN. La comunicación y el periodismo cedieron protagonismo al aceptar las denominaciones de posverdad y fake news para designar la crisis en la circulación textual. La omisión desvió la atención hacia una $-\mathrm{y}$ no únicade las dimensiones afectadas. No hay una inundación de textos falsos, sino fuentes, cuyo origen ha sido o puede ser establecido, que han emitido textos con contenidos discriminatorios $\mathrm{u}$ hostiles hacia terceros, los cuales pueden encuadrarse en categorías conexas a la desinformación. Desde este punto de partida, nuestro objeto parece radicado en las dificultades para controlar una circulación textual descontrolada en un ambiente de plataformas. Este trabajo, basado en los campos de la ecología de los medios y la mediatización, propone otro marco de discusión y otro diagnóstico. Se intentará demostrar que en el nuevo ecosistema no se hacen las mismas cosas, sino que cambian las modalidades, así como las temporalidades, entre otros registros de diferenciación. La transición alteró el control del gatekeeping que ejercían las cabeceras mediáticas e incrementó el tráfico textual, en cuyo flujo se mimetizan las mal llamadas fake news.
\end{abstract}

Palabras clave: medios / plataformas / ecosistema / posverdad / fake news 


\title{
From Media to Platforms. From Control of Gatekeeping to Uncontrolled Conversation
}

\begin{abstract}
By accepting post-truth and fake news as a valid denomination to describe the current crisis of news circulation, journalism and communication's specialists have given up protagonism. This omission turned attention towards one -albeit, not the only one- of the dimensions in question. There is no flood of false texts, but sources that can be, or have been, tracked to its source. These sources have submitted texts with discriminatory or malicious content towards others, which can be framed in categories related to disinformation. From this starting point, our objective seems to be located in the difficulties regarding the control of chaotic textual circulation in a platform-based environment. This paper - which is based on the fields of media ecology and mediatization - propounds a different diagnosis and a different frame of discussion. We will try to demonstrate that, in this new ecosystem, things are done differently, and both modalities and temporalities (among other differentiation registers) change. This transition has altered the gatekeeping control that was once kept by mainstream media and incremented textual traffic, opening the gates to the incorrectly called fake news.
\end{abstract}

Keywords: media / platforms / ecosystem / post-truth / fake news 


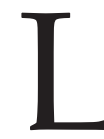

a crisis que se ha abierto en la circulación de textos es la expresión, en el campo comunicacional, de un fenómeno profundo y vasto. Ha sido puesta de manifiesto desde tres influyentes diccionarios (Oxford, Real Academia Española y Collins), que asumieron la responsabilidad de nombrarla a su manera. En diciembre del 2016, el Oxford Dictionary designó al término post-truth como la palabra del año:

After much discussion, debate, and research, the Oxford Dictionaries Word of the Year 2016 is post-truth - an adjective defined as "relating to or denoting circumstances in which objective facts are less influential in shaping public opinion than appeals to emotion".

Por su parte, el Diccionario de la lengua española de la Real Academia Española incorporó el término posverdad en diciembre del 2017, definiéndolo como "distorsión deliberada de una realidad, que manipula creencias y emociones con el fin de influir en la opinión pública $\mathrm{y}$ en actitudes sociales. Los demagogos son maestros de la posverdad". Finalmente, también a fines del 2017, el Collins Dictionary designó como palabra de ese año a fake news, entendiendo por tal: "False, often sensational, information disseminated under the guise of news".

Si bien para el Oxford Dictionary la palabra post-truth se trata de un adjetivo y para la RAE de un sustantivo, hay coincidencias de fondo en las tres instituciones en categorizar la actual confusión en la circulación de textos como perteneciente al orden de la verdad.

Desde nuestro punto de vista, algo que todavía no hemos terminado de dimensionar ocurrió en el pasaje desde un escenario donde el control de la cantidad y calidad de los textos en circulación se concentraba en manos de las cabeceras mediáticas ${ }^{1}$, a otro donde la cantidad de textos se multiplicó en forma exponencial y descontrolada. Vivimos una transición entre el control ejercido por comunicadores a través de las estructuras de múltiples cabeceras, y una circulación que, estimulada por el modelo de funcionamiento de las plataformas, adquirió progresivamente características torrenciales.

Mientras procuramos comprender el fenómeno, se introdujo un agravante: elementos ajenos al ecosistema intervienen en él desde fuera, sin ningún compromiso con las normas que aseguran su supervivencia, las cuales son parte fundamental de los pilares sobre los que se apoya la sociedad abierta. Estas nuevas condiciones, que aún no hemos metabolizado, fueron bautizadas demasiado velozmente como "era de la posverdad" y "era de las fake news". Al

1 Se utiliza el término cabecera mediática para evitar la confusión con el concepto de medio, que se reserva para la categoría general (diarios, radio, TV). Es de uso corriente referirse a "los medios", cuando en realidad se habla de diarios o de emisoras de broadcasting. 
margen de que hay una cierta tendencia a adjudicar casi acríticamente el título de "era" a cualquier tipo de proceso, incluso personalizándolo en figuras de dudosa proyección histórica (¿cuánto debería durar un fenómeno para merecer ese sustantivo?), ni siquiera pueden presentarse pruebas de que la falsedad se haya instalado irreversiblemente entre nosotros.

¿O acaso lo creíble desde siempre no sigue siendo una referencia creíble? También la exageración sensacionalista continúa su reproducción generacional en su búsqueda incesante de multitudes presuntamente fáciles. Lo único que ha cambiado es la presencia de cierto hacking de dudosa procedencia, que parece haberse aprovechado de la permisividad con que las grandes plataformas administran y comercializan casi monopólicamente la publicidad digital. Desde ellas se han emitido, en forma apócrifa, contenidos con una carga por momentos discriminatoria, de manifiesta hostilidad hacia terceros o simplemente de abierta irracionalidad.

El fenómeno adquirió viralidad no gracias al mérito de sus contenidos, sino a expensas de la falta de control de las plataformas que pusieron a disposición de los hackers el potente y sutil recurso del microtargeting. Sin comprender lo que ocurría, el periodismo -incluso el que habitualmente se considera de referencia- se apresuró a hacer lo que no debió hacer, es decir, amplificar el alcance de los infundios, atribuyéndoles una importancia de la que carecían, sin advertir la gravedad implícita en el peligroso intento de influir masivamente mediante el uso de sofisticadas herramientas de persuasión. Este artículo se dedicará a fundamentar estas afirmaciones. Intentemos, en primer lugar, situar contextualmente el escenario.

\section{Entre el gatekeeping y la conversación}

Para McLuhan (1996 [1964]), la verdadera gran revolución ocurrió a fines del siglo XIX con la electricidad, a partir de la cual todo se volvió instantáneo.

La velocidad eléctrica mezcla las culturas de la prehistoria con la hez de la comercialización industrial, al analfabeto con el medio alfabeto y el posalfabetizado. Colapsos mentales de varios grados de intensidad son un resultado muy frecuente del desarraigo y de la inundación con nueva información. (p. 37)

No es fácil asimilar esa comprobación, pero lo llamativo es que sigamos percibiendo el cambio constante como sorpresa, como si fuera lo excepcional, cuando la inestabilidad ya es, desde hace mucho tiempo, la norma. Las inercias suelen ser poderosas e influyentes.

Convengamos en que el cambio más trascendente después de la irrupción de internet en la década de 1990 ha sido la reorganización del ciberespacio en torno a las grandes plataformas. Y, si con la web comenzó la transición de un universo basado en medios y cabeceras mediáticas a otro de plataformas, con estas terminó de materializarse la visualización de la discontinuidad introducida a partir de la irrupción de las redes reticulares. Como en todo 
proceso de cambio, las continuidades son menores a las rupturas, y lo que se pierde suele tener más visibilidad que las ganancias, que por otra parte solo adquieren corporeidad y claridad conceptual una vez consolidadas.

Según parece, tampoco hemos aprendido a no apresurarnos a cerrar - conceptual o nominalmente- procesos que se encuentran en marcha y que no acaban de responder las preguntas que deben responder para clarificar su sentido.

De Kerkhove (1999 [1995]) echa luz sobre este aspecto específico de los cambios en los ecosistemas y utiliza la expresión "dolor de la reestructuración" para denominar a la recuperación tras los cambios inesperados y abruptos que sobrevinieron con la invención de la imprenta de tipos móviles:

Marshall McLuhan y Elizabeth Eisenstein observaron que la invención de la imprenta (que aceleró fuertemente el impacto de la alfabetización manuscrita) estuvo en la raíz de las sangrientas convulsiones religiosas que tuvieron lugar durante el Renacimiento y en épocas posteriores. La transición desde la conciencia colectiva de la Edad Media - basada en el objetivo común de la salvación de la comunidad- hasta el nuevo orden social del espacio público y las mentes individuales requirió varios siglos, caracterizados por una tremenda lucha política e ideológica.

Al final, la inteligencia humana alcanzó unas cualidades de aceleración y crecimiento sin precedentes [...] La objetivación del conocimiento común, almacenado en libros, tratados, diccio- narios, universidades y librerías, garantizó un espacio común, público, social y mental para la libre evolución de las contribuciones individuales. (pp. 225-226)

Sin establecer paralelos lineales entre dos fenómenos separados por cinco siglos, puede hallarse similitudes en cuanto a las consecuencias que impactan en campos impensados e impensables a priori. Es decir, toda vez que un agente de cambio poderoso (la imprenta de tipos móviles, la electricidad, la electrónica) irrumpe, provoca modificaciones, desajustes multidimensionales que cada comunidad social metabolizará a su modo. Digamos de paso - no para detenernos en ello, aunque podría corresponder hacerlo- que el campo de la comunicación ha omitido explicar esta complejidad, razón por la cual a veces parece que no se tomara nota de la razón de los cambios. Es probable que de esa incomprensión provenga la sorpresa que provocan los ciclos de inestabilidad que cada fenómeno abre.

El pasaje de un ecosistema basado en medios a otro basado en plataformas ha provocado un desajuste de profundo calado que incidió en múltiples dimensiones, de las cuales, a nuestros efectos, importa principalmente la comunicacional.

\section{El agotamiento de un contrato de comunicación}

La circulación textual estuvo controlada, desde los comienzos del ecosistema industrial, por las cabeceras mediáticas, 
cuyos propietarios y directores se hacían cargo de la pertinencia de lo que difundían y aun de la impertinencia de lo que decidían postergar o rechazar o, incluso, eliminar. Así funcionaban las cosas desde que los diarios inauguraron las formas periódicas de producción, distribución y consumo de medios en plena Revolución Industrial. ¿Era el único sistema posible? Probablemente no, pero fue el que los diferentes agentes formalizaron como el poseedor de las características esenciales que asegurarían la eficacia de un servicio en el que estaba todo por inventarse. Nada sucede ni funciona de modo ideal e inmejorable en sociedades donde la libertad no solo permite, sino que exige la participación inteligente de los agentes involucrados. Fue el sistema que aquella sociedad instituyó y al que nos habituamos en dos siglos de funcionamiento.

La instalación de las plataformas comenzó con el intento en cierto modo fallido de Napster en el 2001 y el exitoso de Google en 1998, aunque, por el momento, el emblema de las plataformas sea Facebook (2004). Lo cierto es que las plataformas se consolidan a partir de la primera década del siglo xxI y desde hace no más de cuatro o cinco años provocaron cambios fundamentales que cada observador identificará en su propio campo. En la comunicación y el periodismo, debimos lidiar con lo que dio en llamarse posverdad o fake news, finalmente legitimado y validado por tres instituciones como el Oxford Dictionary en el 2016, y los diccionarios de la RAE y Collins, en el 2017.
Los rótulos pueden entrañar una capacidad metafórica, alegórica o eufemística, pero siempre evidencian una línea de razonamiento, unas determinadas hipótesis, un ineludible diagnóstico. Para el caso, la etiqueta se refiere con claridad a que se trata de un conflicto del orden de la verdad. A cuenta de mayor despliegue, conviene señalar desde ya que este trabajo no se ubica en esa línea de razonamiento. No hay un problema en el orden de la verdad, si bien puede parecerlo a primera vista. El desajuste de fondo, como ya se dijo y se fundamentará posteriormente, ocurrió en el orden del ecosistema. Es a partir de la fisura provocada por la transición industrial-informacional que figuras ajenas han aprovechado los momentos de perplejidad y parálisis, que siguen a todo desajuste, para medrar y afectar la confianza en los textos que circulan.

Lo que hace unos dos años era un estado de sospecha generalizada en algunos círculos - los infundios emitidos desde cuentas y perfiles falsos de algunas plataformas habían logrado instalar cierta atmósfera que erosionaba la confianza - se ha generalizado y validado por las prestigiosas entidades académicas señaladas al comienzo. Tanto el concepto de posverdad como el de fake news no solo poseen una carga de diagnóstico con potencial para crear situaciones de alarma, sino también para orientar las investigaciones hacia otros campos (filosófico, político, etcétera) que, si bien constituyen dimensiones en las cuales la crisis ha impactado, desvían la atención del foco 
comunicacional, que es el que nos compete abordar con fines cognitivos.

\section{Fake news, un contrasentido que no debió aceptar el periodismo}

El periodismo no debió aceptar la denominación de fake news, porque lo alude en forma directa. Inocultablemente, noticia es sinónimo de periodismo. No se trata solo de un género, sino de "el género", nave insignia de la profesión. No hay duda de que el rótulo fake news es corto y "entrador". ¿Quién podría no entender de qué se habla? En el plano epidérmico, de comprensión publicitaria, puede advertirse el daño que ocasiona en la percepción colectiva de una profesión y unas metodologías cuyo cometido principal es precisamente contribuir en forma protagónica a la construcción de verdades sociales. Esta afirmación no pretende siquiera aludir a la ya laudada discusión acerca de una presunta objetividad periodística. Ya se ha admitido en forma generalizada que lo que hace el periodismo es construir versiones - múltiples versiones producidas por diferentes voces- que constituyen propuestas que, en definitiva, las audiencias sintetizan y validan de modos complejos, cuyo análisis excede el propósito de este trabajo. Lo que se trata de señalar es que los periodistas son los profesionales que la sociedad legitima para el cumplimiento de ese fin primordial de "hacer saber" algo que hasta el momento se ignora. Es ese punto clave de la profesión el que resulta perjudicialmente afectado por los rótulos mencionados.
No nos detendremos en el aspecto epidérmico e intentaremos argumentar sobre lo que nos parece el fondo del asunto, que puede abordarse desde la pregunta: ¿la crisis en la circulación de textos es un problema en el orden de la verdad?

La profunda cuestión de la verdad tiene un aspecto histórico que se entronca en Aristóteles y en la propia historia constitutiva de la civilización occidental. Resumamos el enfoque del filósofo griego:

Es evidente que a las partes en un juicio no les compete más que demostrar si un determinado hecho es o no es, si ocurrió o no ocurrió. Si es grande o pequeño, si justo o injusto, allá donde no queda definido por el legislador, sin duda le corresponde entenderlo al propio juez, y no aprenderlo de las partes del juicio. Así pues, conviene que las leyes bien establecidas definan todo cuanto sea posible por sí mismas, y dejen a los jueces lo menos posible, primero porque es más fácil encontrar a uno o unos pocos que a muchos de buen discernimiento y competentes para legislar y juzgar; luego, porque la legislación es el resultado de un largo proceso de reflexión, mientras que las sentencias son momentáneas, de suerte que es difícil que los encargados de juzgar decidan adecuadamente lo justo y lo conveniente. Pero sobre todo porque la decisión del legislador no se refiere a lo particular, sino al futuro y a lo general. (Aristóteles, 2005, p. 47)

Como vemos, la preocupación de Aristóteles se centraba en la transparencia de los procedimientos para establecer la verdad. Como esta no existe a priori, se 
trata de construirla - cuando se refiere al derecho y la justicia- con base en tribunales que escuchan a las partes y determinan cuál de ellas aporta los elementos probatorios decisivos. Dado que las autoridades responsables de fallar en cada caso necesariamente contarían con tiempos limitados y escasos, Aristóteles planteaba que la norma fuera lo suficientemente explícita y precisa como para acotar la posibilidad de error. En el periodismo también se hace una construcción, aunque a diferencia del campo del derecho, en que se trata de un fallo con carácter vinculante, la naturaleza de la denominada verdad social - que las cabeceras mediáticas construyen junto a sus usuarios - debe poseer "las tres condiciones en las que se basa la información, o sea: suponer la ignorancia del otro, transmitir un saber, suponer que el otro ha de utilizar ese saber"; todas ellas "pertenecen al proceso de transacción" (Charaudeau, 2003 [1997], p. 52). Como el sentido de la construcción informativa nunca está dado de antemano, con cada información que empieza a circular y de la cual se presentan múltiples versiones - por esa razón, existen tantas cabeceras mediáticas en la sociedad abierta-, se abren procesos más o menos controversiales (dependerá de la gravitación de lo informado) que exhibirán las pujas por la prevalencia de las diferentes visiones e intereses que coexisten en cada sociedad.

Los periodistas conforman una élite profesional legitimada - esta fue otra de las características del contrato de comunicación industrial- para construir esa verdad a la que denominamos social, porque es inevitable que todo lo que alcanza estado público, ya sea gráfico, radial o televisivo, se someta al escrutinio del público, cada vez más activo y atento a las propuestas de sentido. Ese sentido que cada editor intenta imponer, que competirá con las otras propuestas de sentido que legítimamente otros editores intentan, tendrá al público como árbitro. La calidad de ese arbitraje dependerá de innumerables factores que pondrán a prueba las condiciones efectivas de democracia y republicanismo en que se desenvuelve la sociedad. El sistema existe precisamente para que el público esté en condiciones de impugnar, rebatir o discutir cada producto informativo.

Esta actividad, delicada, absolutamente compleja, tiene un papel central en la vida de las sociedades abiertas de tipo occidental, a las cuales en términos sucintos podemos definir como aquellas en donde los ciudadanos cuentan con elementos amplios de juicio y la libertad para adoptar todo tipo de decisiones. Y consiste en una verdadera síntesis de las distintas voces que expresan la mayor cantidad posible de visiones sociales. De su libre juego y del no menos libre intercambio de los usuarios entre sí y con las propias cabeceras, surge la síntesis que Charaudeau (2003 [1997], p. 39) denomina verdad civil, que es la versión provisoria, sometida a constante revisión y discusión, con la que damos socialmente por sentados aun los temas más ríspidos y discutibles. La vida social agota o desplaza unos temas 
y promueve otros en un flujo que no cesa y va diseñando una determinada manera de abordar la agenda mediática y pública que tanto contribuye a definir la forma de ser de una sociedad.

En otras palabras, la verdad construida por las cabeceras - en definitiva, una propuesta de sentido- junto a sus públicos es, por definición, falible y modificable. Su carácter provisional es precisamente uno de sus rasgos principales. Toda verdad será transitoria y adquirirá un estatuto definitivo solo mientras no sea cuestionada.

Esta posibilidad, ante la cual se expone toda verdad -jurídica o periodística-, conecta con otro de los pilares de la sociedad abierta de tipo occidental: la libertad. Porque no es sino sobre la base de la más absoluta libertad para impugnarlo todo que el estatuto de la verdad, tal como fue concebida en los orígenes aristotélicos, tendrá sentido y podrá ser vivido en su completitud. De modo que verdad y libertad forman una doble figura que da por resultado una sociedad de individuos donde ningún poder puede tomar decisiones en nombre de la vida de cada uno de sus habitantes. O sea, una sociedad donde las decisiones vitales están a cargo de quienes deberán finalmente asumir el resultado de sus opciones.

Con lo dicho creemos estar en condiciones de afirmar que ni en el campo del derecho ni en el del periodismo hubo cambios en cuanto a los procedimientos previstos para establecer la verdad. $\mathrm{Y}$ es de establecerla - o sea, de lo que hacemos para asegurarnos de que se tomaron todos los recaudos posibles para acotar la posibilidad de error- a lo que nos referimos cuando hablamos de la verdad. Si se parte de su inexistencia a priori y de la obvia imposibilidad de que alguien con legitimidad la decrete, se habla de una construcción. Nada ha cambiado en torno a la concepción que considera verdadera aquella versión de los hechos que cuenta con las mejores pruebas, las más contundentes evidencias, los datos empíricos más confiables, las fuentes más calificadas. Entonces, no debería aceptarse que el estatuto de la verdad en las sociedades abiertas haya sido alterado como resultado de situaciones que afectan el flujo normal del tráfico informativo.

Quizás exista una percepción confusa en las audiencias sobre las dudas que rodean a la circulación de ciertos textos, y que esta sensación colectiva haya generado una erosión de la confianza. Pero una cosa es la instalación de la sospecha y otra muy distinta, la de otorgarle legitimidad. Si concordamos en que la verdad -los procedimientos para establecerla- constituye, junto a la libertad, uno de los pilares más sólidos de Occidente, no parece conveniente alentar aquellas sospechas, a menos que se posea constancia de que los soportes de la verdad están en cuestión. De lo contrario, nada aconseja apresurarse a ratificar las percepciones, sin una adecuada consideración del punto que garantice adecuadamente el diagnóstico. 
Las garantías de la debida consideración no parecen estar presentes. Ha habido apresuramiento y una de las consecuencias es que se ha provocado una alarma pública respecto a la confiabilidad de lo que circula. Y de esto el principal damnificado es el periodismo.

Aun cuando las instituciones académicas mencionadas (Oxford, RAE, Collins) se hayan equivocado, de ningún modo es un aval para que el periodismo aceptara dócilmente la etiqueta fake news, contribuyendo a validar una situación que no puede sino profundizar los problemas que ya de por sí tenía en esta durísima transición entre el ecosistema industrial y el informacional.

Desde luego, el público no tiene por qué saber - entre otras cosas, porque no se le ha informado- que la noticia no existe hasta que un periodista le dé vida. Antes de que ello ocurra, un hecho, un acontecimiento, un accidente o un conjunto de circunstancias desarticuladas carecen de existencia para el conocimiento general y, por tanto, de sentido. Sencillamente, antes de ser noticia, un hecho es algo que se desconoce y que podría continuar en ese estado. La noticia es una construcción que difícilmente podría resultar falsa. Es inimaginable un medio o un periodista digno de ese título, que emita sostenidamente falsedades como las que hemos visto circular en las redes y a las que se les asigna el rótulo de fake news.

¿Realmente hace falta recordar que, además de los periodistas, los medios cuentan con editores $\mathrm{y}$ directores, o sea, toda una cadena de autoridades y responsabilidades decisorias? Si se considera esta complejidad, puesta al servicio de la información durante todo el día y todos los días del año, pensar que puede haber algo que se denomine noticia falsa parece un contrasentido. Cualquier medio que haya hecho de la mentira su práctica reiterada ha sufrido la consecuente sanción de su audiencia. Esta ha sido una característica verificable de la autorregulación del ecosistema de medios.

\section{Temporalidades: su papel en los cambios}

Los diarios aparecieron a fines del siglo xviII (The Times es de 1785) y se generalizaron a partir del siglo XIX, particularmente después de que Émile de Girardin descubriera la posibilidad de maridar la prensa y la publicidad en La Presse, fundada en 1836. Este hecho ocurrió en el proceso de formación de la ciudad moderna, después conocida como ciudad industrial. A efectos comunicacionales, deberíamos referirnos a ellas como ciudades mediáticas, ya que fueron las primeras donde los medios comenzaron a gravitar.

La sociedad mediática fue también la que vivió por primera vez la novedad de la periodicidad. Hasta entonces, los papeles de noticias eran aperiódicos, es decir que aparecían, o bien porque al poder monárquico le interesaba hacer circular una información, o bien porque a cierto sector político-social le importaba pronunciarse en torno a una 
nueva coyuntura mediante un panfleto. Su propia aperiodicidad le restaba trascendencia más allá de la circunstancia que le había dado origen. Difícilmente pudiera haber surgido una industria de los medios gráficos, si no existían públicos necesariamente aglomerados $\mathrm{y}$ educados en ciudades, mientras no hubiera mecanismos de distribución veloces, como el ferrocarril, y sobre todo mientras no se diera una dinámica social que asegurara una nueva percepción del tiempo, inducida por la propia organización industrial.

Con la ciudad industrial se produjo una aceleración de los ritmos urbanos, tan bien referidos por Benjamin (1986) a partir de las descripciones de Charles Baudelaire (1821-1867) y de Edgar Allan Poe (1809-1849), quienes, además de espíritus gemelos, eran sagaces y pioneros observadores de las nuevas multitudes sociales (pp. 89-99). Surgía, de ese modo, un público que por primera vez iba a esperar con expectativa la próxima edición de unas informaciones cuyo contenido ignoraba, pero que provenían de una fuente emisora que por diferentes razones se había ido ganando su confianza. Junto a la multitud y su turbulenta instalación en el espacio público, nacía también el comprador/lector de productos periódicos. Esa confianza, basada en la credibilidad que el producto de su preferencia generaba en el nuevo ciudadano, es el fundamento del contrato de lectura que cada cabecera estableció desde entonces con sus usuarios.
La temporalidad social y la de los consumos mediáticos están íntimamente relacionadas, por cuanto no puede haber sino interrelación entre la forma en que los individuos de una sociedad viven y perciben su tiempo, y la forma en que los productos de información que consumen se adaptan a esas condiciones. De hecho, el diario, que nace con el descubrimiento de la periodicidad, acaba de agotar su duración junto al contrato de comunicación industrial. Este ya no es esperado por el lector con la misma expectativa de hace cien o cincuenta años; ha sido sustituido por otros productos gráficos -muchos de ellos producidos por las mismas empresas que publicaban diarios- que han establecido un continuo informativo. Obviamente, le seguimos llamando diario, pero es claro que su función se modificó y su consumo ha variado radicalmente.

El advenimiento de una nueva temporalidad, caracterizada por la simultaneidad en el tiempo social y el mediático, es otra de las alteraciones gravitantes en las percepciones sociales que tiene incidencia plena en el fenómeno que abordamos. Parece probable que la inmediatez en la producción y el consumo de textos, introducida por el ecosistema de plataformas, contribuya al establecimiento de nuevas condiciones para su circulación y difusión descontrolada. Asimismo, se produce un relativo desplazamiento de los procedimientos del modelo de gatekeeping, hasta ahora hegemónicos en la producción informativa, hacia nuevas modalidades de intercambio. El filtrado de la información, que 
prácticamente monopolizaban los editores de medios, ya no es el único criterio que rige la circulación de textos, y tiende a ser compartido por flujos conversacionales de características masivas.

Se han mencionado cambios en tres planos. En primer lugar, el pasaje de un escenario de medios a otro donde prevalecen grandes plataformas. En segundo lugar, el paso de la periodicidad a la simultaneidad, con la consiguiente aceleración de los consumos. En tercer término, del filtrado del gatekeeping a la conversación que no filtra. Es decir que el mecanismo que transforma lo privado en información pública, mecanismo que se encontraba en manos de los periodistas, se ha transferido también al público. Más adelante nos referiremos al modelo de producción textual que impusieron las plataformas, que consiste en estimular la mayor cantidad de interacciones por individuo, al margen de su relevancia.

Entre la aceleración de los ritmos sociales, el desplazamiento de las audiencias hacia zonas de emisión de textos multimediales - con herramientas como Facebook Live o Periscope de Twitter, entre otras - y la imposibilidad de que el filtrado periodístico controle con eficacia la circulación de textos, el crecimiento exponencial del flujo ha alterado los marcos y las percepciones. Aquel caudal, finito, abarcable, caracterizado más bien por la escasez y, por tanto, por la generación de cierta avidez para acceder a él, era lo que controlaban y administraban los medios industriales. Ese caudal y sus formas correlativas de administración del flujo resultante son dos de las características centrales del cambio actual. La circulación textual ha cambiado radicalmente su escala y ha desbordado las capacidades operativas de las plataformas.

En estos parámetros se enmarca la crisis desatada por lo que dio en denominarse posverdad o fake news. Lo que ambos términos ocultan en su generalización es que no existe una inundación de contenidos falsos que pudiera justificarlos; lo que sí puede advertirse es la existencia de textos intencionadamente maliciosos que circulan mimetizados en el intercambio torrencial, en muchos casos a partir de cuentas y perfiles de dudoso origen en grandes plataformas.

Parece claro que no hay una deliberada acción de los medios por producir informaciones falsas, y tampoco los usuarios están empeñados masivamente en difundir falsedades. Lo que sí hay son fuentes muy precisas - algunas lindantes con lo delictivoque aprovechan el desajuste operado en el ecosistema para utilizar a su favor las enormes posibilidades tecnológicas en poder de las plataformas.

\section{Lo industrial y lo informacional: esquema comparativo}

Los medios, al igual que las plataformas, son "escenarios donde los agentes humanos interpretan su papel. Al ser ambientes, no delimitan nuestras acciones, pero sí definen la gama de acciones posibles que podemos 
emprender. Facilitan determinadas acciones y nos disuaden de otras" (Strate, 2015, p. 157). La tabla 1 -siguiendo la línea analítica de Strate- compara las diferentes configuraciones del ecosistema industrial del que provenimos, $\mathrm{y}$ el informacional que se instala. Por el tipo de actividades que uno y otro admiten, así como de sus respectivas temporalidades, velocidades, permisos o restricciones, puede advertirse el cambio de ciclo en cuanto a la producción, la distribución/circulación y el consumo de textos informativos.

Como se observa en la tabla 1 , mientras en el ecosistema industrial la

Tabla 1. Comparación entre modalidades de la circulación de textos según ecosistemas

\begin{tabular}{|c|c|c|}
\hline Tipo de acción & Ecosistema industrial & Ecosistema informacional \\
\hline Tipo de estructura que prevalece & Cabeceras mediáticas & Plataformas \\
\hline Quién tiene acceso a los datos & Élites & $\begin{array}{l}\text { Los usuarios eligen } \\
\text { sus prescriptores }\end{array}$ \\
\hline Quién controla su difusión & Editores & $\begin{array}{l}\text { Los usuarios difunden } \\
\text { sus producciones }\end{array}$ \\
\hline Cuánta información se distribuye & La que decida el editor & $\begin{array}{l}\text { La que los usuarios deseen, } \\
\text { sin límites }\end{array}$ \\
\hline A qué velocidad & Secuencial & Hipermediatización aleatoria \\
\hline Cuán lejos viaja & $\begin{array}{l}\text { Local/nacional } \\
\text { (excepcionalmente) }\end{array}$ & Global \\
\hline $\begin{array}{l}\text { Cuánto tiempo va a estar } \\
\text { disponible }\end{array}$ & Según periodicidad del medio & Ilimitada \\
\hline
\end{tabular}

Elaboración propia con base en factores propuestos por Strate (2015, p. 157)

estructura mediática se prestaba para ser administrada por sus directivos, en el informacional las dimensiones de las plataformas y su ritmo de funcionamiento hacen muy difícil el control de un ecosistema donde el usuario cumple un rol mucho más activo. Esto es lo que las plataformas han comprendido y lo que destacan Bell y Taylor (2017):

Las revelaciones sobre fake news en las elecciones estadounidenses del 2016 forzaron a las redes sociales a asumir responsabilidades en el campo de las decisiones editoriales. Contradictoria- 
mente, esto implica una distracción de su foco principal que estructura la economía de las plataformas incentivando la difusión de contenidos de baja calidad, por encima de los materiales de alta calidad. El periodismo con altos valores cívicos, el que investiga al poder o el que cubre a las más desatendidas comunidades locales, resulta finalmente perjudicado por un sistema que favorece la escala y la interacción constante en contenidos compartibles.

Las plataformas no son medios, y cuando, como Facebook, intentan ubicarse como árbitros de la credibilidad y ordenar el tráfico noticioso, les va muy mal. Los medios, en cambio, provienen de otro ecosistema y, desplazados de su centralidad, no han logrado delinear nuevas políticas ni han encontrado aún formatos creativos en sus relaciones con las plataformas. No obstante, su papel continúa gravitando, como comprobó empíricamente una investigación del Instituto Reuters (2017), que abordó el alcance de los sitios identificados como emisores de contenidos engañosos en Francia y en Italia. El estudio pudo establecer fehacientemente que el alcance de estos es ciertamente insignificante, comparado con la presencia muy significativa de los medios tradicionales. Los datos indican que los sitios web identificados como dedicados a desinformar en Francia e Italia no superaron el $3 \%$ de la población online en ninguno de los dos países, frente a medios populares como Le Figaro, con 22,3 \% de audiencia, y La Repubblica, con 50,5 \% (Hazard Owen, 2018).

De todos modos, esta metodología no alcanza a dimensionar el problema de las mal llamadas fake news, ya que no abarca el microtargeting ocasional de los espacios publicitarios vendidos por Facebook y Google a perfiles falsos (que es donde se encuentra el verdadero problema). No era el objetivo de la investigación $\mathrm{y}$, por tanto, no es del caso exigirle esos datos. Pero, para obtener una visión panorámica completa del fenómeno de la desinformación, es imprescindible abordar la investigación de los perfiles que no osan decir su nombre y emiten mensajes apócrifos, y ello implica la revisión de los mecanismos mediante los cuales las plataformas administran el microtargeting.

\section{El verdadero problema que las plataformas no han podido (querido) controlar}

Las plataformas no ocultan que sus principales beneficios provienen de lograr que los usuarios se incorporen a sus estructuras y realicen en ellas la mayor cantidad de movimientos y acciones, sobre todo cuando estos generan a su vez nuevos movimientos y acciones de otros usuarios. Que su forma de rentabilizar sus prácticas radique en promover la interactividad sin límites ha sido un riesgo de toda cultura mediática. $\mathrm{Y}$ en el modelo de las plataformas ese riesgo asume el carácter de una cadena sin solución de continuidad en procura de la interacción continua de centenares de millones, el verdadero activo que ofrecen a las marcas de cualquier ramo.

Estamos ante una ecuación similar a la de los medios cuando tenían 
(tienen) que ofrecer audiencias numerosas; a ningún comprador de espacio publicitario le resulta útil una audiencia escuálida. Pero, además $-\mathrm{y}$, en realidad, esta es la clave que justifica la ingente acumulación de datos-, de este modo las plataformas disponen de una herramienta de altísimo potencial, como es la capacidad algorítmica de orientar publicidad de cualquier tipo hacia el público que el comprador del espacio indique. Clics y venta de espacios publicitarios para que quien los contrate pueda enviar sus mensajes ultradirigidos (microtargeting) a grupo objetivo, tal es el modelo de obtención de beneficios de las plataformas.

Obviamente, no es lo mismo utilizar esta poderosa herramienta de marketing cuando se trata de propiedades inmuebles o productos turísticos, que cuando entra en juego la propaganda electoral, sobre todo en procesos como el del brexit, cuyas consecuencias para la comunidad británica y para el conjunto europeo gravitarán por décadas. Una tercera posibilidad vuelve a esta herramienta un grave peligro social: la situación que se crea cuando quienes contratan el espacio no se identifican con claridad, o utilizan perfiles falsos y generan cuentas inexistentes que emiten decenas de miles de posts con capacidad de impactar en millones y hasta centenares de millones de usuarios vulnerables, es decir, susceptibles a la influencia de andanadas publicitarias bien estructuradas.

A Facebook, por ejemplo, le advirtieron reiteradamente -entre ellos el entonces presidente Obama en noviembre del 2016- que la plataforma estaba siendo utilizada por parte de fuerzas ilegítimas. Aprovechaban momentos de confusión y caos causado, como ya vimos, por la enorme dificultad de controlar un tráfico torrencial de textos, para influir no solo a favor de uno de los dos candidatos que competían por la presidencia de Estados Unidos, sino fundamentalmente para debilitar las bases republicanas mediante la siembra de mensajes de odio y discriminación.

Veamos la siguiente secuencia. Después de negar reiteradamente las denuncias, Facebook terminó reconociendo que 470 cuentas rusas falsas habían comprado espacios por valor de 100000 dólares en la plataforma, y desde allí emitieron más de 3000 anuncios que llegaron a unos 70 millones de usuarios entre el 2015 y el 2017. Recordemos que las elecciones en Estados Unidos se llevaron a cabo el 7 de noviembre del 2016. A partir de ese reconocimiento, se desató el debate y la presión política sobre la compañía para que entregara información detallada al Congreso. El 22 de septiembre, The New York Times informó que Facebook prometió entregar los enlaces de las cuentas rusas al Congreso. El jueves 21 del mismo mes, Mark Zuckerberg había declarado en San Francisco lo siguiente:

“[...] importa muchísimo el proceso democrático y proteger su integridad. Me preocupa que usen nuestras herramientas para minar nuestra democracia". Y también Colin Stretch, responsable legal de Facebook, agregaba: “El público merece saber de manera concreta qué pasó 
en las elecciones del 2016. Hemos concluido que compartir los anuncios que hemos descubierto encaja con nuestra obligación de proteger la información de los consumidores". (Jiménez Cano, 2017)

Es claro que todo lo que haga o diga Facebook tendrá la trascendencia que le otorgan sus más de 2000 millones de usuarios. Esa inconmensurable influencia se la conferimos los ciudadanos de las sociedades abiertas que le hemos reconocido a la empresa la eficacia de resolver problemas básicos de la comunicación contemporánea a escala planetaria. Las plataformas no existirían si no potenciaran las actividades humanas con una mezcla de velocidad y eficiencia comunicativa que las torna imprescindibles en el funcionamiento social actual.

Sin embargo, Facebook presenta incongruencias severas en aspectos cruciales que empiezan a quedar de manifiesto al tiempo que parece emerger cierta conciencia colectiva del desmedido poder que administran las corporaciones tecnológicas. Repasemos algunas de ellas. En julio del 2017, Facebook declaró no tener pruebas de que cuentas falsas hubieran comprado espacios publicitarios en la plataforma. Un mes después, en agosto, reconoció que "470 perfiles y páginas estaban relacionadas con la Agencia de Investigación de Internet de Rusia, una organización vinculada al Kremlin" (Jiménez Cano, 2017). Finalmente, en diciembre del 2017, no solo admitió la existencia de un problema generalizado con la emisión de textos maliciosos desde perfiles apócrifos, sino que anunció que permitiría a sus usuarios ver los contenidos de los mensajes que publicaron esas cuentas, según el sitio online The Hill (Facebook allows users to view past interaction with Kremlin-linked content, 2017). Es decir que quien así lo quisiera podría verificar si había sido utilizado en su buena fe para compartir textos engañosos.

La plataforma cuenta con herramientas sofisticadas que pone al servicio de su negocio, pero no a disposición de la sociedad que la alberga y le da sentido. Ante las primeras advertencias, Facebook podría haber realizado una auditoría interna para comprobar si realmente existían las anomalías denunciadas. Como no lo hizo, y muy poco tiempo después debió admitirlas, cabe suponer que lo sabía y optó por negarlo, pensando quizá que la verdad no iba a aflorar. La actitud de Facebook no solo no ha sido cristalina ni cautelosa, y sí negligente, por cuanto en muy poco tiempo debió hacer lo que en su momento no hizo y aceptar lo que había negado. Hoy está claro que la plataforma había vendido, a sabiendas - ¿cómo ignorarlo?-, espacio publicitario a cuentas sin identificar.

La pregunta es ¿Facebook puede volver a hacerlo? Y la respuesta es que sí, puede. Es de esto, precisamente, de lo que Facebook elude hablar. La alternativa más plausible para aspirar a tener cierto control de la situación por parte de las autoridades parece radicar en un monitoreo estricto de los mecanismos mediante los cuales las plataformas comercializan el espacio publicitario. 
La estrategia comunicacional de las plataformas ha sido exitosa para evitar que los debates más influyentes se hayan centrado en este punto crucial. Y distraer la atención de ese aspecto del problema ha contribuido a la línea de razonamiento que opta por ubicarlo en el orden de la denominada posverdad y fake news. Este diagnóstico ha tenido la consecuencia - desfavorable para el periodismo y la comunicación- de conducir a gran cantidad de periodistas a pensar, de absoluta buena fe, en soluciones para acotar lo que consideran la irreversibilidad de una situación en que la verdad habría dejado de importar. El rótulo-diagnóstico condujo a que muchos profesionales se sintieran, si no culpables, responsables de una situación que no los interpela. El periodismo $\mathrm{y}$, por ende, muchos periodistas se han transformado en vehículos involuntarios de una estrategia comunicacional que, por el momento, puede caracterizarse de inadecuada.

\section{Casos que ilustran el descontrol}

\section{ProPublica: ¿qué considera Facebook mensaje de odio?}

En una investigación cuyos resultados se publicaron en diciembre del 2017, periodistas de la organización periodística sin fines de lucro ProPublica comentaron una investigación de la propia ONG que observó 43 casos con decisiones discutibles e incluso contradictorias de los moderadores de Facebook. En 22 de ellos, dicen los investigadores, se comprobó la violación de las propias reglas de Facebook. ProPublica se propuso indagar cómo administra Facebook lo que denomina discursos de odio. Es decir, ¿qué significa para Facebook discurso de odio y cómo aplica sus propias reglas? (Varner, Tobin, Angwin y Larson, 2017).

Nuestro análisis acerca de cómo Facebook implementa sus reglas sobre discursos intolerantes muestra cómo sus moderadores (reviewers) a menudo adoptan diferentes criterios acerca de permitir o borrar contenidos similares. Subrayamos esta inconsistencia en tres pares de posts que hablan de los mismos temas. Además, llamamos la atención de Facebook sobre otros 43 posts, de los cuales la compañía reconoció que había cometido errores en 22 instancias y defendió sus fallos en 19 de los demás casos².

Los estándares comunitarios de Facebook prohíben las amenazas violentas contra las personas, por motivos vinculados a sus creencias religiosas. De modo que cuando una lectora de ProPublica, Holly West, vio la publicación de una foto acompañada del texto "El único musulmán bueno es el musulmán muerto", ella lo reportó como discurso de odio a través del sistema de reporting de la plataforma. Facebook declaró que la foto era aceptable y le envió a Holly West un mensaje automático que decía:

2 ProPublica no aclara qué ocurrió en los dos casos restantes. 
"Volvimos a controlar nuevamente la foto y pensamos que no va contra ninguno de nuestros estándares, aunque comprendemos que pueda resultar ofensivo para usted y otras personas".

Sin embargo, Facebook eliminó, sin comentarios, un post que decía "Muerte a los musulmanes" que los usuarios habían reportado reiteradamente. Tanto en uno como en otro caso, se registra una violación de las normas de Facebook, pero solo uno de ellos llamó la atención de alguno de sus 7500 censores o reviewers; la pregunta es ¿quién decide qué se permite y qué se rechaza? Después de que le formuláramos la pregunta, Facebook también eliminó el otro post y se disculpó. (Varner et al., 2017)

Interesa destacar que, según ProPublica, el mensaje que Facebook le envió a su usuaria fue automático; esto no es solo un estilo de época, sino parte de la naturaleza operativa de las plataformas. Si bien todo se puede automatizar, resulta obvio que, más allá de ciertos límites, la automatización puede poner en riesgo innecesario a situaciones y personas. Según parece, la ausencia de marco normativo en torno a los límites de la automatización no es la mejor de las opciones.

El informe de ProPublica, que puede consultarse en su web, es muy específico en cuanto a señalar pormenorizadamente cada una de las incongruencias detectadas, así como las respuestas recibidas (Varner et al., 2017). Automatización y cantidad de moderadores han sido los ejes de todas las respuestas que ha dado Facebook a las quejas, protestas y denuncias por sus reiteradas fallas. $\mathrm{O}$ sea: mejorar el algoritmo e incrementar el número de reviewers. Ambas soluciones, si es que realmente se pusieron en marcha en alguna de las oportunidades en que fueron anunciadas, demostraron ser probadamente ineficaces.

\section{TripAdvisor y YouTube: dos ejemplos de descontrol}

TripAdvisor es otra red que trabaja con los mismos estándares: atraer el máximo de usuarios que califiquen los productos y servicios que utilizan. Su objetivo es transformar a la plataforma en un reducto de imprescindible consulta y referencia para todos cuantos deseen consumir esos productos y/o servicios por primera vez. El sistema parece inobjetable, pero no todo funciona según las previsiones en un universo fuera de control.

Según informaba el diario La Nación (Argentina), con base en BBC Mundo, en diciembre del 2017 un bloguero que sospechaba de los estándares descontrolados de TripAdvisor decidió lanzarse a probar sus hipótesis en el sector gastronómico de Londres: "El restaurante que en siete meses se convirtió en el mejor de Londres en TripAdvisor sin existir".

Así lo confesó el propio bloguero de la revista Vice, Oobah Butler, en su post. ¡Antes de trabajar en el popular medio, Butler trabajó en una plataforma que vendía reseñas falsas en webs como TripAdvisor y Yelp! Escribir reseñas falsas por 10 libras le hizo pensar si existirían restaurantes falsos. En abril del 2017, decidió comprobarlo por sí mismo montando el suyo propio en Londres: The Shed at Dulwich (El cobertizo de 
Dulwich) [...]. Al comenzar su iniciativa, el cobertizo ocupaba el último puesto de TripAdvisor, el 18 149. En poco tiempo y con la ayuda de amigos y gente cercana que realizaron reseñas falsas se colocó entre los mejores 10 000. Se hizo tan popular que Butler empezó a sufrir las consecuencias de la fama de su cobertizo con constantes llamadas, e-mails y reservas con una antelación de 4 meses que esquivaba como podía. Y, al final, el 1 de noviembre logró lo que se había propuesto: era el número 1 en el ranking de restaurantes de Londres.

Nada es lo que parece en el universo de las plataformas.

\section{YouTube: 400 horas de video cada minuto}

En marzo del 2017, se produjo un éxodo de grandes anunciantes de YouTube debido a que sus marcas quedaron expuestas a ser asociadas con contenidos discriminatorios. La Vanguardia de Barcelona dio cuenta de esta información el 23 de marzo.

Todo empezó en febrero del 2017 con una investigación del diario The Times, en la que cientos de videos de extremistas, nacionalistas y filoterroristas en YouTube aparecían rodeados de anuncios de multinacionales como Argos, Walmart, Starbucks, Pepsi o incluso anuncios del propio Gobierno del Reino Unido [...]. El éxodo pronto cruzó el charco y firmas estadounidenses que dejan en Google millones de dólares al mes, como los operadores de telecomunicaciones AT\&T o Verizon, la empresa de transportes Enterprise o el conglomerado Johnson \& Johnson, decidieron cortar por lo sano. A mediados de esta semana, Google entró en pánico ante la salida de varios de sus mayores anunciantes. Su director ejecutivo pidió perdón, y prometió varios cambios que mejorarían la diferenciación del contenido "sano" y del contenido "fuera de sus directrices". (Barredo, 2017)

Simultáneamente, se divulgó que en YouTube se descargaban 400 horas de video por minuto. Difícilmente puede haber algo que no se desajuste en medio de tal aluvión de material videográfico. ¿Cómo evitar que una marca que quiere promocionar las virtudes de su producto quede expuesta a materiales que exhiban valores opuestos? El ecosistema centrado en plataformas ha desafiado las posibilidades de control con su potencialidad de intercambio y viralización. La modalidad basada en contenidos de calidad variada y acceso gratuito, provistos por decenas y hasta centenares de millones de usuarios, que son a la vez consumidores de esos mismos contenidos, si bien estimula el flujo incesante de contenidos de interés, también presenta contradicciones aparentemente insalvables para las estructuras de control previstas hasta el momento.

Según parece, las plataformas no pueden y la sociedad tampoco sabe cómo conminarlas a hacer lo que prometen dentro de los marcos normativos vigentes. Google, Facebook y Twitter aseguran que reformularán sus algoritmos y, por ahora, la sociedad ha optado por creerles, sin que se pueda saber o conocer los criterios con base en los cuales se producen 
las modificaciones y ni siquiera si estas realmente se producen.

\section{Conclusiones: en los límites del ecosistema}

En medio del cambio radical de la temporalidad introducido por la simultaneidad de los tiempos mediático y social, el ecosistema informacional basado en plataformas ha mostrado rápidamente sus límites a través de las dinámicas que las propias plataformas inauguraron. Los nuevos comportamientos de centenares de millones de usuarios de todos los continentes, pero básicamente los de las sociedades abiertas de tipo occidental (en los países no occidentales, las redes y plataformas enfrentan una variada gama de restricciones y prohibiciones), condujeron a situaciones inéditas en la circulación de textos, que desde hace algún tiempo encienden las alarmas en varias dimensiones sociales.

Importa establecer la idea de que el ecosistema tocó sus límites por cuanto el descontrol observado parece favorecer la reiteración del uso de mecanismos con capacidad de alterar o distorsionar procesos político-sociales relevantes como unas elecciones de jefes de Estado (Estados Unidos, Francia, Alemania) o la secesión nacional o confederal (Cataluña en España, el brexit en el Reino Unido). Contamos con suficientes elementos de juicio como para profundizar el análisis y advertir que, de prolongarse las actuales condiciones, se ampliará la inestabilidad y confusión comunicacional. Desplegado en la cabal expresión de sus capacidades y límites, el ecosistema de plataformas revela dificultades de autogestión que pueden comprometer zonas vitales de la sociedad.

Quizá el pasaje de un ecosistema a otro parezca repentino o abrupto, probablemente porque no hayamos comprendido los múltiples cambios previos que, como en todo proceso complejo, operan acumulativamente hasta completar su sentido. En realidad, se trata de un ciclo que maduró a lo largo de casi dos décadas. Esa historicidad, aunque breve y reciente, nos compele $y$, al mismo tiempo, nos facilita la búsqueda del mejor diagnóstico para abordar un escenario frente al cual abundan las muestras de incomprensión. Los rótulos posverdad o fake news que ha recibido la crisis de la circulación de textos, y que en la dimensión comunicacional impacta sobre todo en la credibilidad de los textos que circulan, parece interpelar a periodistas y comunicadores. Por eso, este trabajo ha pretendido cuestionar ambos rótulos y argumentar que no es el periodismo quien debe hacerse cargo de la confusión resultante.

El manejo desaprensivo de una herramienta de alta sofisticación como el microtargeting, unido a que las plataformas disponen de la mayor cantidad concentrada de datos personales de la historia humana, ha sido uno de los factores - si no el principal- que causan esta crisis que ha afectado, entre otros, al campo comunicacional. La emisión de infundios desde perfiles apócrifos y con capacidad de impactar en millones de perfiles seleccionados a priori ilustra 
con claridad que las plataformas han manejado inescrupulosamente la instancia de compraventa de sus espacios publicitarios.

Lo verdaderamente relevante para este trabajo es que tales emisiones apócrifas se enmascaran en el tráfico torrencial de textos que ha puesto en movimiento el ecosistema informacional. Si se mira superficialmente el fenómeno, podría pensarse que el problema radica en el fluir intenso de los textos, cuando esa es una característica propia de las condiciones informacionales, que otorgan una libertad inédita a los usuarios. El núcleo del problema está en la facilidad con que, quien se lo proponga, accede al corazón del sistema de las plataformas y emite desde allí lo que desee contra quien desee. Dichas emisiones han contaminado el resto del sistema, dado que se mimetizan en el velocísimo flujo que caracteriza a las condiciones de instantaneidad e inmediatez que prevalecen en la temporalidad actual. Es decir que esos contenidos apócrifos con frecuencia encuentran en el torrente textual audiencias confiadas en la buena fe de los emisores, que los comparten y reproducen en un encadenamiento sin solución de continuidad y fuera de control.

En resumen, creemos haber aportado argumentos demostrativos de que la denominación posverdad y fake news parcializan el enfoque y lo acotan en una medida que dificulta la búsqueda del foco de esta crisis. Quienes crearon o impulsan la utilización de estos términos han partido de la percepción de que la cantidad de textos falsos o "que distorsionan deliberadamente una realidad", como señala el diccionario de la RAE (2017), es tan significativa que justifica su uso, aun a costa de los riesgos que esa generalización pueda entrañar. Desde nuestro punto de vista, ese extremo no solo no está probado, sino que es probable que tampoco logre superar las pruebas de la investigación empírica.

Lo que no se ha hecho, y es a lo que tenemos que abocarnos, es la operación metodológica de desagregar, para una misma plataforma y en un período álgido determinado, los posteos espontáneos e interactivos de cuentas reales con seguidores reales y contenidos reales, del flujo fraguado, a menudo con contenidos sospechosamente similares, desde cuentas apócrifas y escasos seguidores, quizá tan falsos como sus perfiles. De este modo, podría no solo determinarse que las características cualitativas de uno y otro flujo difieren radicalmente, sino que también difieren cuantitativamente: mientras uno es torrencial y de orígenes ampliamente diseminados, el otro se emite a partir de fuentes originales ínfimas. Este procedimiento parece más científico y apropiado que el de unir ambos tipos de textos en un mismo y único haz indiferenciado, con lo cual tiende a magnificarse un fenómeno que, de analizarse con detenimiento y precisión, probablemente se advierta como mínimo, acotado y controlable.

Desde nuestro punto de vista, el problema puede definirse a partir de un plano más profundo y abarcador como el de la circulación de textos y el incremento exponencial de la escala, provocada a su 
vez por la transición entre ecosistemas. Por tanto, y sin pronunciarnos en cuanto a si corresponde o no caracterizar esta crisis con categorías alusivas a la verdad, no dudamos en afirmar que ha sido un error del periodismo avalar e incorporar esas denominaciones a la construcción informativa habitual. Normalizar expresiones como fake news equivale, si no a cohonestar la tesis implícita en su uso, al menos, a generalizar la sensación de dudas sobre la credibilidad en los textos que pone a circular una profesión cuya legitimidad depende precisamente de la calidad de la verdad y sentido que sea capaz de producir.

\section{Referencias}

Aristóteles. (2005). Retórica (Trad. D. Bernabé). Madrid: Alianza Editorial.

Barredo, A. (25 de marzo del 2017). Grandes empresas abandonan YouTube tras ver sus anuncios en videos extremistas. La Vanguardia. Recuperado de http://www.lavanguardia.com/tecnologia/20170325/421171814349/youtube-google-publicidadinternet-terrorismo-extremismo.html

Bell, E., y Taylor, O. (29 de marzo del 2017). The Platform Press: How Silicon Valley Reengineered Journalism. Recuperado de https://www.cjr.org/tow_center_reports/platform-press-how-silicon-valley-reengineered-journalism.php

Benjamin, W. (1986). Sobre el problema de la filosofía futura. Barcelona: Planeta; Agostini.

Charaudeau, P. (2003 [1997]). El discurso de la información. La construcción del espejo social. Barcelona: Gedisa.

Collins Dictionary. (2017). The Collins Word of the year 2017 is... fake news. Recuperado de https://www.collinsdictionary.com/woty

De Kerkhove, D. (1999 [1995]). La piel de la cultura. Investigando la nueva realidad electrónica. Barcelona: Gedisa.

El restaurante que en siete meses se convirtió en el mejor de Londres en TripAdvisor sin existir. (16 de diciembre del 2017). La Nación. BBC Mundo. Recuperado de http://www.lanacion.com.ar/2091909-el-restaurante-que-en-siete-meses-seconvirtio-en-el-mejor-de-londres-en-tripadvisor-sin-existir-ni-servir-un-soloplato

Facebook allows users to view past interaction with Kremlin-linked content. (23 de diciembre del 2017). The Hill. Recuperado de http:/thehill.com/policy/ technology/366223-facebook-releases-tool-to-let-users-see-russian-contenttheyve-interacted

Hazard Owen, L. (31 de enero del 2018). Here's a first attempt to quantify the extent of Europe's fake news problem. Recuperado de http://www.nie- 
manlab.org/2018/01/heres-a-first-attempt-to-quantify-the-extent-of-europesfake-news-problem/

Jiménez Cano, R. (22 de septiembre del 2017). Facebook cooperará en la investigación por la trama rusa. El País. Recuperado de https://elpais.com/internacional/2017/09/21/estados_unidos/1506031105_189056.html

McLuhan, M. (1996 [1964]). Comprender los medios de comunicación. Las extensiones del ser humano. Buenos Aires: Paidós.

Oxford University Press. (2016). Word of the Year 2016 is: post-pruth. Recuperado de https://en.oxforddictionaries.com/word-of-the-year/word-of-the-year-2016

Real Academia Española; Asociación de Academias de la Lengua Española. (2017). Posverdad. En Diccionario de la lengua española. Recuperado de http://dle.rae. es/?id=TqpLe0m

Reuters Institute (2017). Measuring the reach of "fake news" and online disinformation in Europe. Recuperado de https://reutersinstitute.politics.ox.ac.uk/our-research/ measuring-reach-fake-news-and-online-disinformation-europe

Strate, L. (2015). Estudiar los medios como medios. McLuhan y el enfoque de la ecología de los medios. En C. A. Scolari (Ed.), Ecología de medios: entornos, evoluciones e interpretaciones (pp. 147-163). Barcelona: Gedisa.

Varner, M., Tobin, A., Angwin, J., y Larson J. (23 de diciembre del 2017). Facebook's Uneven Enforcement of Hate Speech Rules Allows Vile Posts to Stay Up. Recuperado de https://projects.propublica.org/graphics/facebook-hate 
